Article

\title{
Incessant Conceptual/Industrial Transformation of Automobiles
}

\section{Fumio Kodama}

Research Center for Advanced Science and Technology, University of Tokyo, Tokyo 153-0041, Japan; kodama_5@ga2.so-net.ne.jp

Received: 31 May 2019; Accepted: 24 July 2019; Published: 30 July 2019

\begin{abstract}
In order to comprehend the prospect of a future automobile industry, the development path of the automobile industry is reviewed. It is found that the industry has experienced an incessant conceptual transformation, dominant design, emission control, fuel efficiency, product integrity, modularization, and hybridization. An industrial transformation is also identified, comprised of inter-firm competition, inter-industry competition, and inter-industry collaboration. It is concluded that in the coming age of self-driving, global partnering including IT companies will forge a new path for industrial development. Additionally, the pattern of innovation will involve business model creation rather than simple product/process innovations, such as the PC industry experienced after its stand-alone innovation had been accomplished.
\end{abstract}

Keywords: Dominant design; Product integrity; Modularization; Hybrid car; Self-driving; Industrial transformation

\section{Introduction}

A perspective on the technology of the automobile industry can trace the four distinct types of technologies: product, manufacturing, commodity, and societal technologies. The basic components of product technology were developed and perfected in the nineteenth century by such individuals as Daimler, Benz, and Dunlop. This product technology was transferred to the United States and improved upon by Ford. Ford's major achievement was, as everyone knows, the development of manufacturing technology, i.e., the conveyer belt system with interchangeability of parts. In the 1920s, however, consumers began to demand fashion and comfort in their cars. With these new market trends, Alfred Sloan of GM created commodity technology, including the closed body, the full-line policy, the consumer credit system, and a distribution system for used cars [1].

In the 1960s, when the diffusion rate of cars surpassed one car per two persons in the United States, people began to recognize a societal disadvantage of car usage-pollution. Thus, the development of a new technology was required to overcome this problem. This technology was quite different from the commodity technology developed by GM. We call it "societal technology" because it made the survival of the car in society possible [2]. The Japanese contributions to developing this societal technology are obvious [3]. However, these are only half of the history of automobile industry. They should be extended into the 21st century.

Indeed, automobile technology has undergone incessant transformation. Its conceptual transformations are made up of dominant design [4], emission control, fuel efficiency, product integrity [5], modularization [6], hybridization, and self-driving. Along with these conceptual shifts in technology at each of time horizon, we find an industrial transformation: inter-firm competition, inter-industry competition, inter-industry collaboration, and global partnering.

Based on the incessant nature of automobile technologies, we will provide an empirical view of the disruptive nature of self-driving technology. Although many scholars have claimed that disruptions 
brought about by self-driving technology can be compared with recent ICT disruptions [7], i.e., after the Internet was introduced, no empirical discussions exist. In this context, we will review what happened with the diffusion of PCs before and after the Internet revolution.

\section{Dominant Design and Experience Curve}

The conventional theory of technological competition is based on the principle of dominant design, which was originally developed to explain the automotive industry [4]. According to this theory, when a new technology rises there is considerable uncertainty over which of the possible variations will thrive. After a period of time, however, one or a few of the variants come to dominate the others. Effective competition then takes place on the basis of both cost and performance.

A number of authors have conducted empirical studies to test the universality of the dominant-design theory. Utterback and Suarez, in particular, began with the following hypothesis: before the emergence of a dominant design, there will be an increase of entering firms with many types of the product; following a dominant design, there will be a wave of exits, and amalgamation in the industry [8]. Therefore, they argued, the total number of participants in the market at any point of time will start with a moderate increase, followed by a much steeper rise, demonstrating a wave of replicating firms, peaking at the point when a dominant design emerges, and then declining rather drastically until it reaches a stable state.

In short, they tried to prove the existence of dominant design indirectly, through a time-series counting of participating companies in a given product market. Among others, their study included automobiles. In their curves for automobiles, the total number of firms dropped consistently after a dominant design was established until a stable state was reached. Furthermore, the peak of the curve matched with the identified date of dominant design. The year with the largest number of firms in the automobile industry, 1923, was the year that Dodge introduced the dominant design (the all-steel, closed-body automobile).

Another theoretical base of measurement of the automotive development is what is called "experience curve". In fact, Abernathy [9] at Harvard Business Review drew the curve for average price of the Ford T in the time period from 1909 to 1923 in an experience curve format (a logarithmic scale of average list price and of cumulative units produced). They discovered a steady declining curve. However, the long-term declining trend only continued until the emergence of General Motors and of Chrysler in the 1930s. At Ford, the experience curve was not indefinite; it dominated only the Model T era. Then, Ford abandoned a performance-maximizing strategy in which the company continued to improve performance yearly at an ever-higher product price. In the meantime, the market was shifting. In the early 1920s, consumer demand began moving toward a heavier, closed body and more comfort. General Motors quickly responded to this shift with new designs.

Alfred Sloan, architect of GM's strategy, later wrote: "With its light chassis, it was unsuited to the heavier closed body, and so in less than two years (by 1923) the closed body made the already obsolescing design of the Model T noncompetitive as an engineering design". In May 1927, Ford closed his River Rouge plant and kept it closed down for nearly a year to retool, leaving the field to Chevrolet unchallenged and providing an opening room for Chrysler's Plymouth. Ford lost the lead to General Motors (Sloan, 1964) [10]. However, it should be noted that the competition pattern remained as an inter-firm all through the various shifts in the automobile technology before the pollution problem emerged.

\section{Emission Control and Inter-Industry Competition}

Many scholars have stated that regulation does not always discourage the societal diffusion of new technologies but sometimes actually triggers the diffusion process. The mechanism by which a new regulation accelerates the diffusion of technology may work for producing a new technology, even in a conventional industry, when a drastic change in regulation becomes socially indispensable. To consider this possibility, we will look at how the Japanese auto industry realized "technological 
profiting" when it developed new technology first to comply with the change in emission standards and then to accommodate economic concerns about fuel economy.

After the local pollution problems of automobiles were somewhat resolved, the two oil crises made society aware of another disadvantage to the automobile - the waste of precious nonrenewable resources. The increase in Japanese car exports in 1975 and 1979 coincided with the two oil crises and the increase in crude oil prices. Figure 1 makes visible the technological dynamics that occurred between regulatory changes in emission standards and the improvement in the fuel economy. As shown in the figure, the Japanese government successively raised emission standards for passenger cars so that the allowable upper limits for emissions were drastically reduced between 1960 and 1978 .

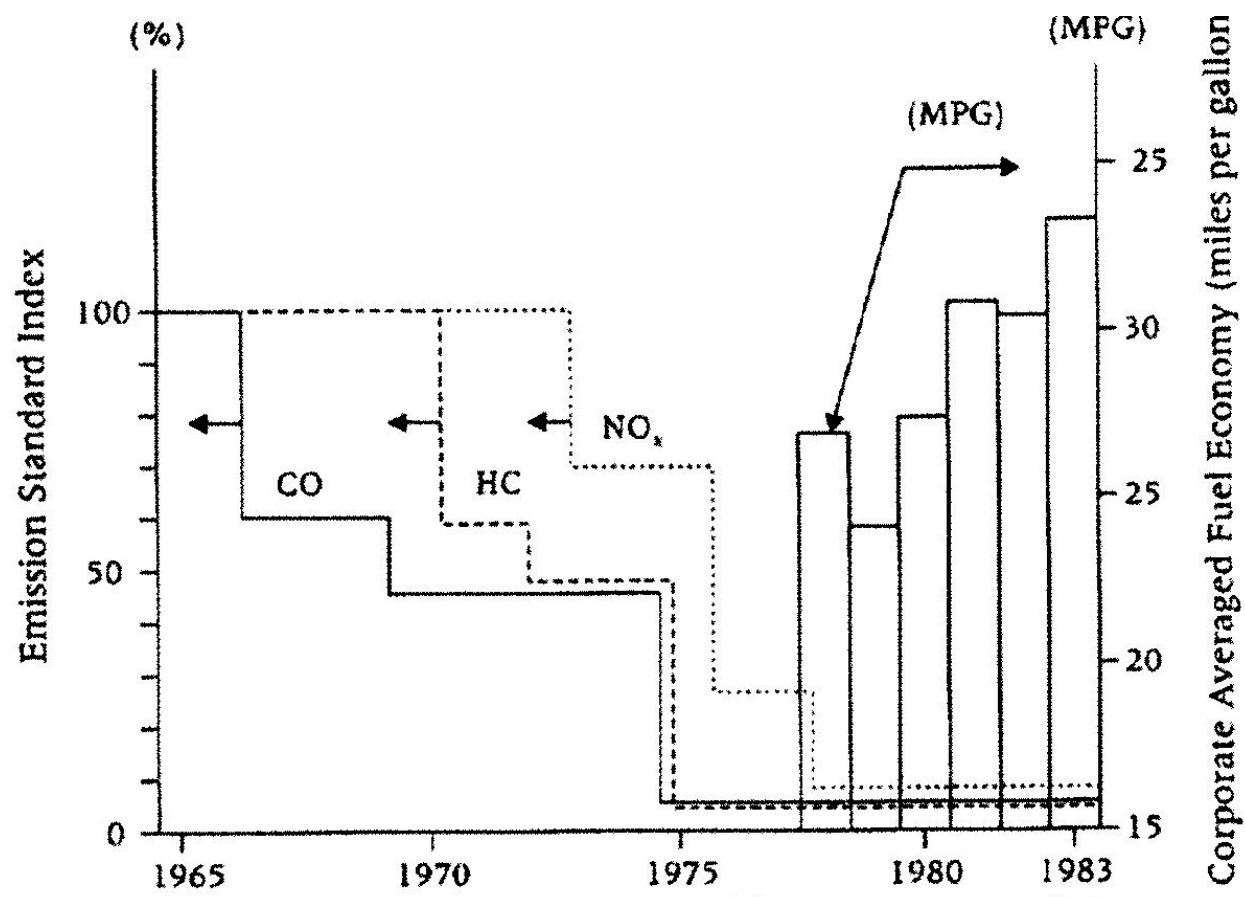

Figure 1. Dynamic relation between emission regulation and fuel economy improvement. Note: Fuel economy improvements are represented by Toyota's corporate fuel economy.

In a public hearing before the Japanese Diet, Honda said that it was feasible to comply with the emission standards proposed by the government. This statement led to the government's decision to set the most severe standards in the world at that time, and the Japanese auto industry invested a vast amount of money and power in anti-pollution technology. To comply with emission standards, Japanese car manufacturers made substantial R\&D investments, which entailed improvements in fuel economy after 1979. In fact, Japanese manufacturers were to discover that emission standards and improvement in fuel economy were "two sides of the same coin" as far as R\&D efforts were concerned.

In hindsight, the requirement for emissions control turned out to be technologically equivalent to fuel efficiency. In order to comply with emission standards, Souichiro Honda, a founder of Honda Motor Co. Ltd., directed the company's researchers to focus on a deeper understanding of the burning process of fuel inside the cylinder. When commodity technology was critical to competitiveness, this research area had been neglected by the auto industry worldwide because it did not contribute to a company's competitive edge (This story is based on the author's private conversation with Mr. Honda at Saitama University's Graduate School of Policy Science, 1985). Honda's technological strategy resulted in the invention of its CVCC (compound vortex controlled combustion) engine, enabling lean-burn, and controlled fuel injection technology. As a product, the Honda Civic with its CVCC engine achieved the best fuel efficiency in the U.S. auto market until 1980. Indeed, it is easy to see that Honda's accumulated knowledge about the burning process in the cylinder helped to improve fuel 
economy. Burning fuel cleanly is technologically equivalent to burning it "efficiently", especially in terms of designing the engine configuration.

The development of a new engine configuration was also related to the competition among Japanese car manufacturers at that time. Most auto manufacturers were newcomers to the industry [11]. Honda had been manufacturing motorcycles; Toyota, textile machinery; and Matsuda, tricycles for light-freight transportation, and Subaru and Mitsubishi had moved from their prewar business in airplanes to passenger cars. To a motorcycle manufacturer such as Honda, developing a totally new model was regular practice. Whenever one of its motorcycles does not win a competition, Honda will redesign its engine. This approach, however, was not the approach of firms that had always been in the auto industry. They would have preferred to develop a chemical catalyst that would remove the pollutant after the fuel was burned in the cylinder. Both Toyota and Nissan took this approach, as did U.S. auto manufacturers. Regulatory changes, then, sometimes work to revitalize a conventional industry. New entrants from different industries can enrich technical variations created to comply with new regulations. By doing so, newcomers not only benefit from changes in regulation but also profit technologically.

After Honda's invention of CVCC engine triggered the Japanese government to drastically reduce in 1970s the allowable limits for emissions by automobiles, the other Japanese auto manufacturers responded to this change in regulation, by commercializing three-way catalyst technology (a multicomponent material containing the precious metals rhodium, platinum, and palladium; ceria $\left(\mathrm{CeO}_{2}\right) ; \gamma$-alumina; and other metal oxides) (The 2002 Honda Prize was awarded to Dr. Barry John Cooper, who developed the systems for the reduction of harmful hydrocarbons for gasoline engine by using the three-way catalysts and the CRT systems to remove carcinogenic carbon particles from diesel engine). This development involved a wide range of industries, including materials industry.

However, it should be noted that the final stage of problem-solving did not include the chemical industry. The three-way catalytic converter was designed to eradicate exhaust pollutants, i.e., carbon monoxide, unburnt hydrocarbons, and nitrogen oxides. The conversion efficiency of the three-way catalyst, however, differs among different kinds of pollutants, depending upon the air/fuel ratio, as depicted in Figure 2. This figure shows that the conversion efficiency can be quite high across the three pollutants, but only in the middle range of air/fuel ratio. Therefore, chemical industry assumes that they can solve the problem but only if they can delete all the three kinds of pollutants all at once.

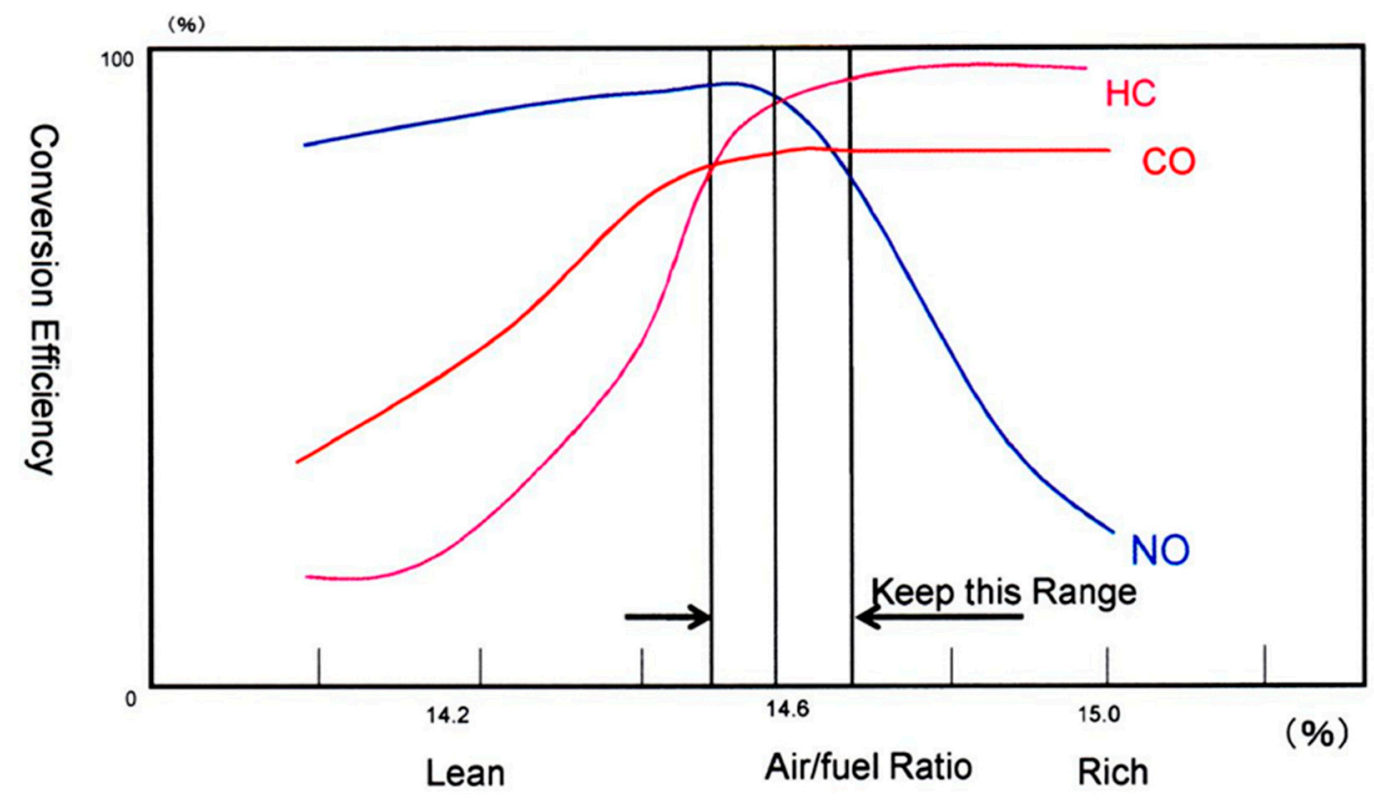

Figure 2. Changes of conversion efficiency of three pollutants along the air/fuel ratio. 
However, the auto industry articulated the needs for emission control by interpreting this diagram in a different way. Why not just control the engine operation so that the air/fuel ratio remains always in this narrow range? The auto industry thought that they could do this through the use of electronics, i.e., the conversion efficiency could be kept high all through different pollutants, if they could keep the air/fuel ratio in a certain range. Therefore, this competition, which is interindustry, not interfirm in an industrial sector, has created a new industry called the catalyst industry. In fact, the catalyst manufactures association was established by leaving chemical companies out of their membership and now covers 60 companies in their membership.

\section{Product Integrity: Learning-by-Decomposing}

Two oil crises caused the shift in the US automotive market from gas-guzzlers to small cars in which the Japanese manufacturers had an advantage. The biggest impact that this shift had on the eco-system of car manufacturing in the United States was on the manufacturer-supplier relationship. Ford used to outsource 50\% of their parts. The world's largest auto manufacturer, GM, used to outsource $30 \%$ of their parts. On average, US auto manufacturers had a higher degree of vertical integration than their Japanese counterparts. In 1988, however, GM separated out Delphi Automotive Systems, and left the long-held tradition of "self-sufficiency" behind by saying that this was a landmark for GM (CNN, 1998/8/3). They said that the vertical integration had been a major success factor for GM since its foundation in 1908, but that it had become a minus rather that plus (Automotive News, 1998/8/10).

In Japan, on the other hand, three quarters of total value added of a car were produced by suppliers. Additionally, the Japanese automotive supplier industry is vertically organized. In other words, they are organized as a hierarchical, multitier structure among suppliers in terms of customer-supplier and equity-holding relationships. Meanwhile, a Chrysler CEO at that time asserted that they could reduce costs by using a reciprocal system built on long-term trust: a target price was negotiated reciprocally, and the profits are shared in case the real price was below the targeted price negotiated (Nikkei, 1988). Indeed, another important character of the Japanese automotive supply system lies in the fact that "reciprocity" exists in the car design between manufactures and suppliers. In other words, the hierarchy alone cannot assure the product "integrity". A contracting system has to exist between the manufacturer and the suppliers in which the suppliers can test their products and make experiments, in order to accommodate the specifications made by the manufacturer.

By making a contrast in manufacturer and supplier relationship between the United States and Japan, we can assert that the Japanese system has become a "world standard". Therefore, we are interested in why and how the Japanese eco-system of automotive parts supplying works effectively in generating and diffusing knowledge concerning the automotive manufacturing. We will investigate the process by which knowledge of manufacturing developed by manufacturers and suppliers diffuses effectively through the Japanese system of automotive part supply. In other words, we are interested in how knowledge is transferred from manufacturers to parts suppliers and embodied in suppliers' capabilities of technology development, through the hierarchy existing between the manufacturers and the suppliers and through the reciprocal design activities between them.

First of all, we will formulate the necessary conditions for product integrity to be realized. The automotive system of manufacturing should be comprehended as a nesting system in which a lower hierarchy is nested in an upper hierarchy of automotive manufacturing. Therefore, the decision on "make or buy" of an automotive part is based on where they put the boundary lines in every level of the multiple hierarchical structure. On these boundary lines, the generation and diffusion of knowledge arises [12]. Therefore, it is absolutely crucial to know how the supplier system will be decomposed. It is this decomposition that makes possible the generation and diffusion of knowledge of automotive manufacturing. It is well known that automotive manufacturers develop their manufacturing machines and equipment—dies, tools, specialized machines, and robotics—for themselves more often in Japan than in the United States. This means that the design capability of manufacturing machines is owned 
by the automotive manufacturers. This system can articulate the specific requirements for suppliers, and these requirements are precisely transmitted to suppliers through the hierarchical and reciprocal supplying system of automotive parts. Thus, by establishing appropriate decomposition of automotive parts supplying system, we can effectively and precisely diffuse the articulated requirements to all the relevant suppliers [13].

What is a sufficient condition for guaranteeing product integrity? How can the knowledge generated be embodied in the production lines of suppliers? In the Japanese automobile industry, there exits two distinct types of contract system between manufacturers and part suppliers: detailed-controlled parts and black-box parts. In the contract of the black box parts, the manufacturer gives only the rough specifications to suppliers, and the supplier makes a detailed design and submits the drawing to the manufacturer for the manufacturer to approve. Nishiguchi [14] argued that this contract system evolved through "bilateral design" activities between manufacturers and suppliers. The essence of this system lies in the reciprocity in the design activity between them. Therefore, we can call it "reciprocal system". In the contract system of the detail-controlled parts, on the other hand, the manufacturer designs in detail and lends the detailed drawing to suppliers in order to let the suppliers produce the designed parts as the manufacturers specify. We call this "non-reciprocal system". In 1972, the reciprocal parts consisted of only $24 \%$ of all the contracts, while in 1992 these parts consisted of as much as $55 \%$ of all the contracts. This contracting system prevails not only in the first-tier suppliers but also in the contract between the first-tier and second-tier suppliers.

The first-tier suppliers are those that have direct relationships with vehicle manufacturers; the second-tier suppliers are those that have indirect relationships with vehicle manufacturers via first-tier suppliers. Since membership in the Japan Automotive Part Industry Association (JAPIA), a trade association of parts suppliers, includes all the first-tier suppliers but only a few second-tier suppliers, statistical data available through the Association do not represent an accurate picture of the Japanese supplier industry. In order to understand the differences between the first-tier and second-tier suppliers, therefore, we conducted a survey of the structural characteristic of the Japanese automotive-supplier industry (thus, any attempt to describe the structural characteristics of the second-tier suppliers would make sense, given the importance of the hierarchical structure and the limited availability of the statistical data, and enhance our understanding of the industry. Since the purpose of the survey is to understand the structural characteristics of the industry at this second level, the sampling of the suppliers was designed so that the relationships between the second- and first-tier suppliers would be clear. Eight first-tier suppliers were asked to select 60 firms that they considered their second-tier suppliers, and all the numerical data from the second-tier suppliers were compared with those from the first-tier suppliers) within the Joint U.S.-Japan Automotive Study at the University of Michigan [15].

As to the nesting hierarchy, we found that all the first-tier suppliers had an equity holding relation with the auto manufacturers, while only the one fifteenth of the second-tier suppliers had a direct equity relation with the auto manufacturers. However, about one-third of the second suppliers had equity relation with the first-tier suppliers.

As to the contract system, we found that as much as $91.7 \%$ of first-tier suppliers employed the reciprocal contracting system, while $74.8 \%$ of second-tier suppliers adopted the reciprocal system. In other words, only one quarter of the second-tier suppliers employed the non-reciprocal system. As far as the differences in the product category were concerned, the majority of the second-tier suppliers of product category of "electrical and electronics" parts were allowed to employ the reciprocal contract. However, in the category of driving/steering parts and of chassis/breaking parts, only $30 \%$ of second-tier suppliers were allowed to employ the reciprocal system.

When we entered the 1990s, however, it seems that the issue of product integrity became less important. A clear indication of this trend is that the share of "reciprocal" contract system, which presupposes that a heavy negotiation between the manufacturers and the first-tier suppliers decreased after 1990. Additionally, this decreasing trend became solid thereafter, as shown in Figure 3. We 
speculate that this decreasing trend has something to do with the digitalization (electronization) of car components, which will be discussed in the next section.

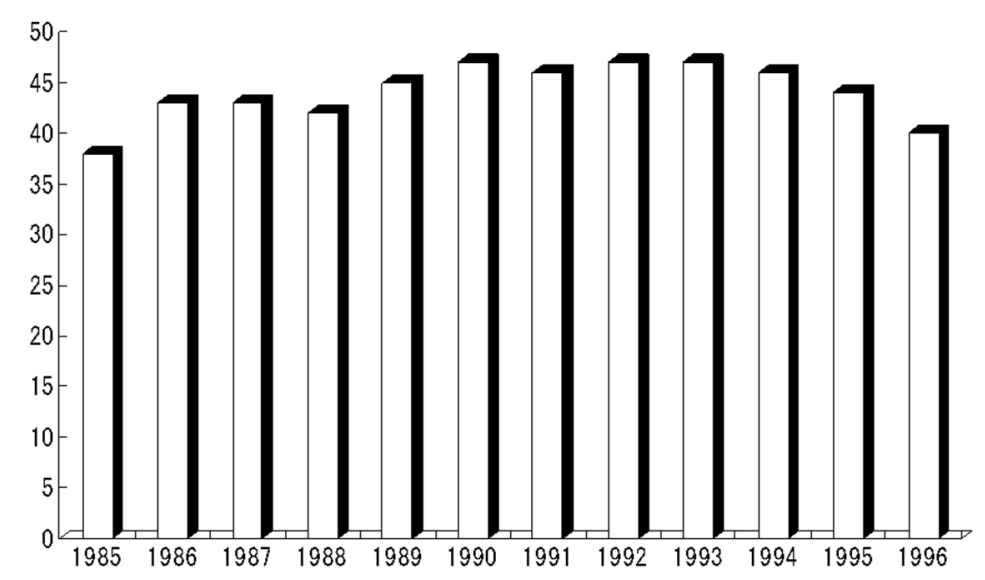

Figure 3. The change in the share of the reciprocal contracts. Source: the author of this paper was personally provided by the company with these statistics.

\section{Modularization and Electronic Control Units}

In 1980s, the computer industry was vertically integrated. Around 1995, however, the industry shifted towards horizontal competition, because computer manufacturers began to procure various components and combine them [16].

However, in the automotive industry it has been claimed that modularization was not as explicit during the 1980s because the competition was focused on the product integrity, especially on internal integrity [5]. In the 1990s, however, the big assemblers in automotive manufacturing began modifying their tightly centralized design. Automotive designers are now trying to parcel out the design of their complex electromechanical system [17]. This is due to the modularization of automobile structure triggered by the digitalization of automotive parts.

In our study of modularization in the automotive industry, we hypothesized that this shift would be reflected in patenting activities. For our measurement, we used a patent database called PATORIS (Patent Online Information System), a systematic online search system of patent information in Japan. The information in this database goes back to 1955 and contains about 40 million entries, as of around 2000. Therefore, patent counting was conducted for the following four categories of control systems: engine control, chassis control, safety control, and communication control systems. (more specifically, engine control system includes electronic control for fuel injection, vaporizer, and muffler. Chassis control system includes electronic controls for automatic transmission, suspension, antilock-breaking system, traction, four-wheel drive, and power steering. Safety control system includes such items as air bag, back sonar, automatic wiper, automatic air conditioner, cruise control, and keyless entry system. Communication control system includes such items as car navigation system, display meter, and optical communications system). It should be noted that this categorization is different from that used for analyzing the structural modularity of the automobile. We chose an appropriate combination of several key words to represent each of the four controls systems. Based on this procedure, we compiled the patent applications in every year from 1976 to 1998. For each control system, we calculated the ratio of automotive assemblers in patent application, as shown in Figure 4. 


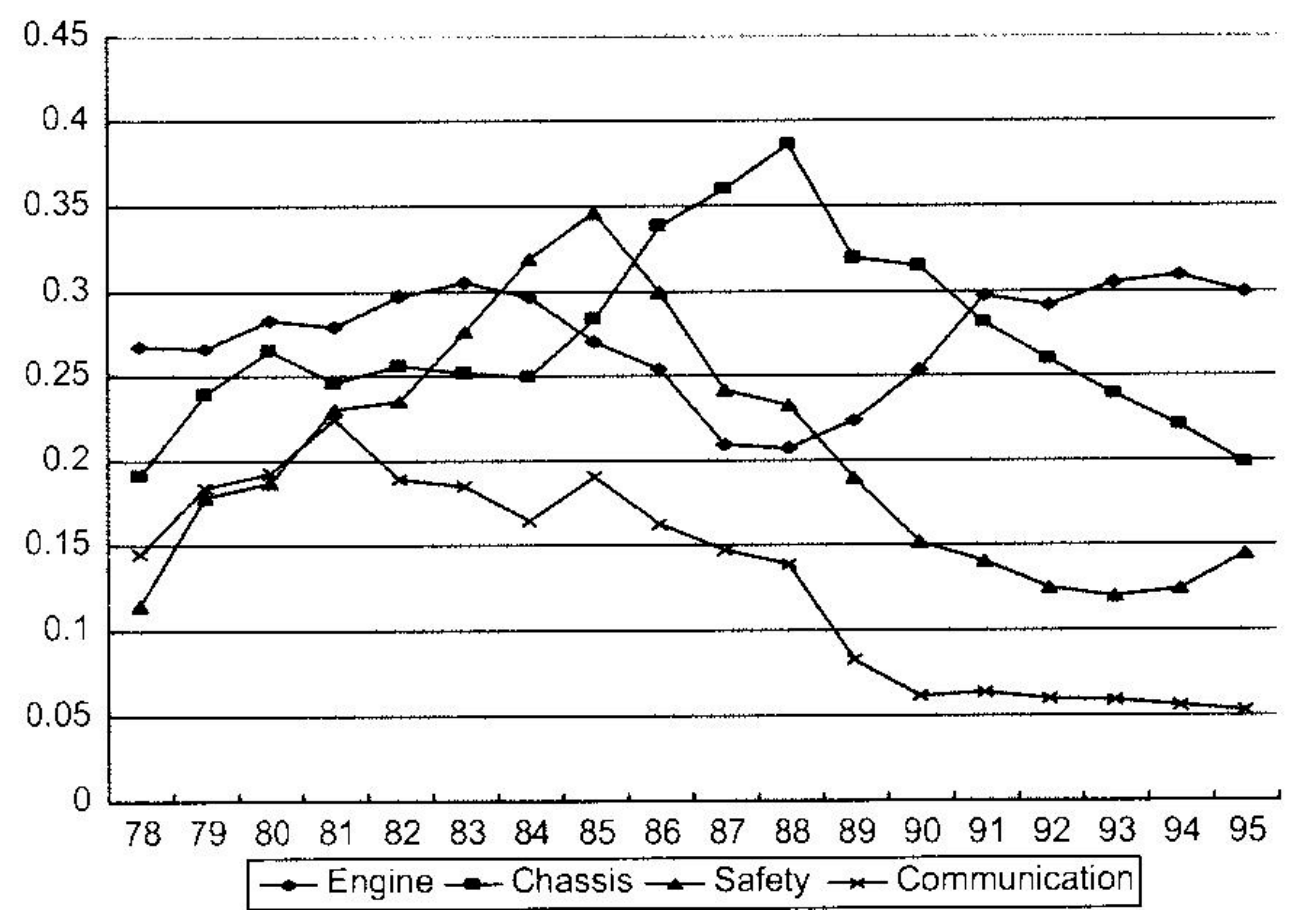

Figure 4. Changes in shares of automotive assemblers in patent applications. Source: Ogawa, H. (2000) [18].

As can be seen in the figure, the shares of automotive assemblers did not drop much in the 1980s, and some of them rose in systems like chassis and safety control. In the 1990s, however, these shares started falling in chassis control, safety control, and communication control systems. This indicates that modularization proceeded abruptly when the automotive industry entered the 1990s. However, we must note that there is one observable exception to this trend of modularization - the engine control system. The share of automotive assemblers in engine control system rose in 1990s, i.e., modularization did not advance. This is different from the case of PCs, in which modularization did advance in all the components. Therefore, we are interested in analyzing why modularization in the engine control system did not advance in the 1990s, while modularization is discernable in other automotive control systems.

We hypothesize that the differences in modularization were related to the differences in digitalization of the automotive components. The technological base of the digitalization of automobile's control systems consists of the three elements: a sensor, an actuator, and an electronic control unit (ECU) that is located between sensor and actuator. The sensor detects the change occurring outside the system and transmits it to the ECU, And the actuator manipulates the system operation based on the command received from the ECU. Therefore, the critical component of the electronization of automobiles is the ECU, which is equivalent to the computer. Already in 1995, approximately ten ECUs were installed in a small car (for the electronics-controlled automatic transmission, the power steering, the powered windows, the angle adjustment of mirrors, and the control of the air conditioner). The bigger cars were equipped with about 20 ECUs, and the high-class cars had more than 30 ECUs (As of 2006, approximately 50-60 ECUs were mounted on an average car (Nikkei, 27 March 2006)).

Therefore, we attempted to measure the degree of digitalization in terms of the relative value of ECUs built in each control system (specifically, the production value of ECUs for each control system was divided by the total value of automotive parts production. In other words, the relative economic weight of ECUs built in each control system was used for the index of digitalization.) The measurement results show that digitization in engine control systems has not advanced, or rather there is a declining trend, while digitalization has proceeded drastically in the other three control systems, as seen in Figure 5. 


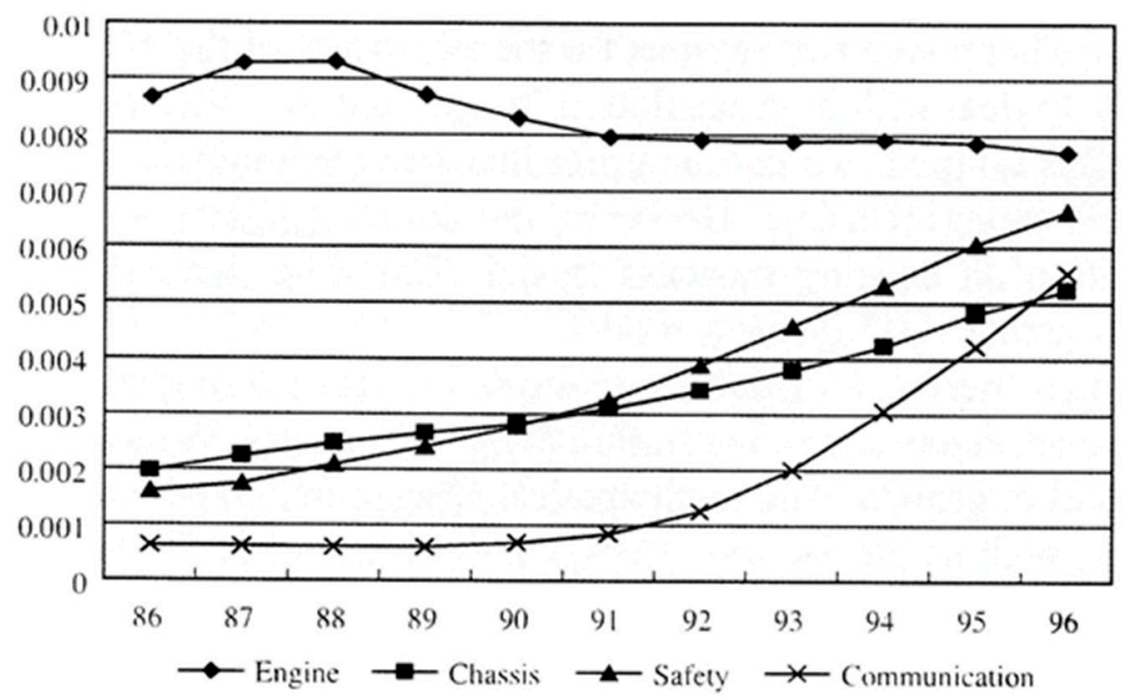

Figure 5. The weight of electronic control unit (ECU) in each category of automobile control systems. Source: Ogawa, H. (2000) [18].

This comparative measurement of modularization in PCs and automobiles alludes to the relationship between the degree of modularization and the diffusion of digital technologies. The deeper the penetration of digital technologies is, the further advanced is the modularization. Indeed, the introduction of digital technologies makes modularization possible and drives the industry towards horizontal competition. In an industry where not all the technologies are digital, as is found in the automobile industry, the technological leadership of assemblers remains as conspicuous as it was before.

\section{Hybridization: Interindustry Collaboration}

Responding to the enlarged social demand for global climate protection, the automotive industry has been searching for a new path toward technological developments, including hybrid, electric, and fuel cell vehicles. This means that the assemblers' development has to be more concentrated on engine design. The follow-up study on patent counting is shown in Figure 6.

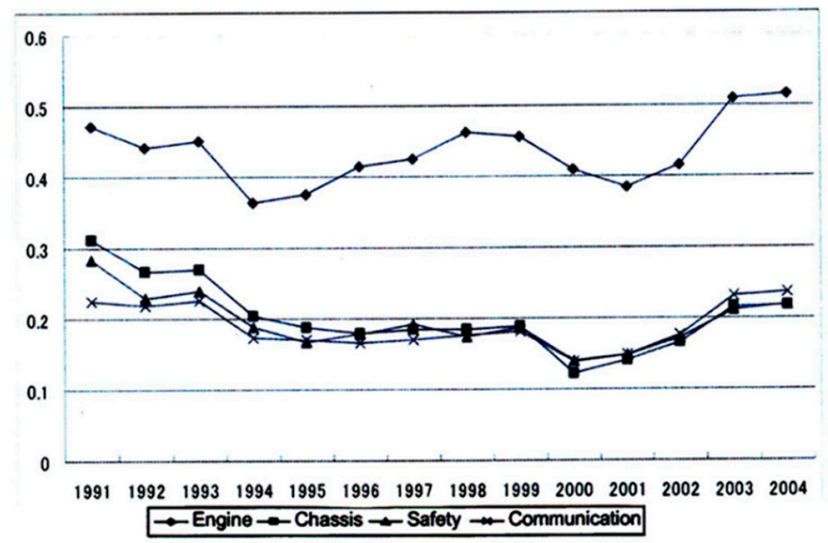

Figure 6. Changes in shares of automotive assemblers in patent application, 1991-2004.

As seen in the figure, the assemblers' share in the category of "engine" began increasing again in 1995, and this increasing trend continued more or less until 2004, while their shares in other categories kept decreasing. Toyota was the first to develop and market a gasoline engine-electric motor hybrid vehicle, the Prius. The hybrid system of the Prius exploits a combination of gasoline engine and electric motor switching on the driving condition. Under a light load, only the motor drives the vehicle to save 
energy and reduce emissions. When the vehicle is under a high load, the gasoline engine is switched to power the vehicle and charge the battery for the motor. The hybrid system realizes substantial improvements both in fuel efficiency and in reduction in $\mathrm{CO}_{2}$ emissions. Carbon monoxide (CO) and nitrogen oxides $\left(\mathrm{NO}_{\mathrm{x}}\right)$ emissions are also substantially reduced to one-tenth of the previous level. Over the 3-year period since its introduction, the Prius achieved drastic worldwide sales of over 50,000 by the end of the year 2000 .

It is noteworthy that the success of the hybrid system was possible because the management of Toyota clearly articulated two goals: twice the previous fuel efficiency and extra-low emissions, from the start of the development. Toyota was able to manufacture an automobile system by integrating component technologies for engines, motors, inverters, batteries, and breaks. In order to overcome this integration problem, it was necessary for Toyota to absorb technology from outside the company as well as to develop a new technology by themselves. In order to complete the development of the hybrid engine, Toyota had to outsource its electric battery technology. We will describe how Toyota outsourced its battery and gradually digested its technology (this concerns the dynamics of open innovation in hybrid car development).

Toyota's recognition that they were lacking in experience regarding the electric battery led to their cooperation with Panasonic, resulting in their outsourcing of the development of the battery from Panasonic. Thus, the first Prius was introduced in December of 1997, and the battery was manufactured totally by Panasonic. The dynamics of collaboration are made explicit by investigating joint patent application statistics. Toyota's joint patent application began in the late 1997, and five joint patents were lodged before the sales of the first Prius. The joint application was implemented through the jointly established company, Panasonic EV Energy (PEV) Co. The number of joint applications increased drastically and peaked at around 2000. During this period, the joint effort was made to develop the lighter and smaller battery, which brought minor changes in the 2000 model.

In September of 2003, the brand-new model of the Prius was introduced, the volume of the battery was reduced by half, and the weight was reduced to $40 \%$ of the first model. Thereafter, the number of joint applications drastically reduced and Toyota became the largest stock holder of PEV Co. The number of patent applications in the IPC patent code of H01M is plotted in Figure 7, in which the number of single applications and that of joint applications are depicted separately.

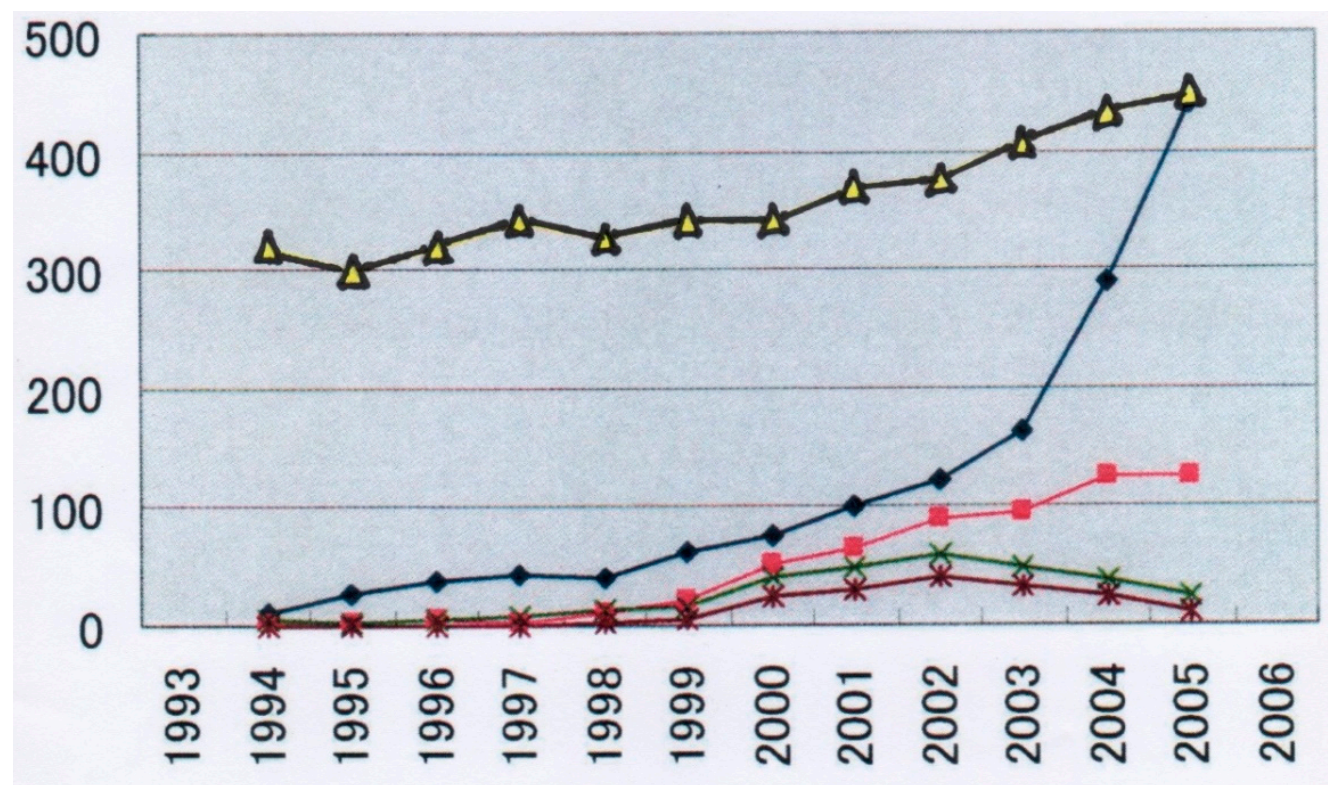

Figure 7. Patent applications by Toyota and Panasonic. Source: Hayashi, M (2008) [19].

As seen in the figure, the number of Panasonic patents $(\Delta)$ far outnumbered that of Toyota $(\downarrow)$ and the majority of the joint applications had Panasonic as the principal applicant. This reflected the 
technical leadership of Panasonic. After the joint development was finished, however, the number of Toyota's patent applications persistently increased and became the same as Panasonic's. This indicates that Toyota successfully acquired knowledge of battery manufacturing through their participation in the joint development with Panasonic. In other words, Toyota succeeded in internalizing and transferring the battery technology so that this technology better fit the specific needs of automobiles.

In the interindustry, regarding competition of developing three-way catalyst technology, as described above, the automobile industry could commercialize this technology by utilizing its own competency. In order to reduce the $\mathrm{CO}_{2}$ emission in terms of enhancing fuel efficiency, on the other hand, the hybrid engine system was developed through the use of electric battery provided by an electric company. Only after their outsourcing from Panasonic could Toyota articulate their need for a hybrid engine battery. Indeed, Toyota reduced the volume of the battery by half, and the weight to $40 \%$ of the original model, by their efforts of absorbing the battery technology from Panasonic. In other words, an interindustry collaboration was necessary to solve problems in the global environment, and it is obvious that a greater widening of industrial participation will be an absolute necessity, as the problem is ever-shifting in its nature.

\section{Self-Driving and Final Morphing of the Auto Industry}

We once had the experience of "global partnering" among the world's automobile companies. The trends immediately after the oil crises stimulated demand in the main auto markets more than ever. Responding to this situation, U.S. auto manufacturers and suppliers developed a global strategy involving the worldwide integration and coordination of product development, production, and marketing. For GM, these developments were represented by the "world-car" concept [2]. In contrast, Japanese manufacturers had been hesitant to move offshore. The Japanese have, by and large, avoided worldwide sourcing.

During the age of the Fourth Industrial Revolution, however, the idea of world car should be pursued in a different context, i.e., in the context of "self-driving". The German National Academy of Science and Engineering [20] published a report about what is now called "Industry 4.0". The first three industrial revolutions were realized as a result of mechanization, electricity, and IT. Now, the introduction of the Internet of Things and services into the manufacturing environment is realizing the Fourth Industrial Revolution. In the future, businesses will establish global networks that incorporate their machinery, warehousing systems, and production facilities in the form of cyber-physical systems (CPS). In a similar context, Schwab [21] argued that the Fourth Industrial Revolution is characterized by a fusion of technologies that is blurring the lines between the physical, digital, and biological spheres. The incessant shift from simple digitization (the Third Industrial Revolution) to innovation based on combinations of technologies (the Fourth Industrial Revolution) is forcing companies to reexamine the way they do business (The First Industrial Revolution used water and steam power to mechanize production. The Second used electric power to create mass production. The Third one used electronics and information technology to automate production. Now a Fourth Industrial Revolution is building on the Third, the digital revolution that has been occurring since the middle of the last century).

Therefore, the development of self-driving should be framed as the fusion between the physical and cyber spheres. Therefore, we can call it "sphere fusion" rather than simple technology fusion. Where is the auto industry heading? At least, we can ascertain that the development of self-driving is going to create various types of business models that are not confined to the transportation industry. However, where can we find a reference case and data?

In her book on the history of the Internet, Abbate [22] summarizes its history as follows: computing technology underwent a dramatic transformation. The computer, originally conceived as an isolated calculating device, was reborn as a means of communication. When computers were scarce, expensive, and cumbersome, using a computer for communication was almost unthinkable. Innovations that occurred in the PC (personal computer), therefore, created new ways of using one after another. In other words, the PC technology created new systems-of-use [23]. According to Anderson and Tushman [24], 
an industry evolves through a succession of technology cycles. Each cycle begins with discontinuity based on new technologies, along economically relevant dimensions of merit. In each case, a process with inherently higher limits redefines the state of the art, increasing machine capacity by an order of magnitude while lowering costs and improving quality. This discontinuity is based on a breakthrough in system-of use [23], i.e., the creation of a new business model. By reviewing a long history of the auto industry, we might argue that while a breakthrough in technology starts the first cycle, a breakthrough in the business model will inaugurate the second cycle.

Foster [25] once formulated the difficulty in managing technological discontinuities as movements from one technology to another with inherently higher upper limits. Now, we are interested in visualizing the differences in the growth patterns between printers and PC technologies as well as the difference between market-driven and market-driving growths [26,27]. Sharif and Ramanathan [28] proposed a market-growth model in which the potential adopter (upper limit) increases over time in the following three models:

Model A: Potential market size does not change: TV

Model B: Potential market size increases by two steps: breakthroughs; printers

Model C: Potential market size increases continuously: business model creation.

Market growth data was collected for televisions (yearly production data: 1956-1980) as an example of model A. Market growth data was collected for printers (monthly production data: 1983.01-1998.08) for Model B. For Model C, market growth was collected for PCs (monthly production data; 1987.01-2001.06). To identify the market growth patterns for these three product categories, we conducted a statistical fitting of these three kinds of growth models described above (For the identification of the most appropriate model, we will use the criterion developed by Akaike. The AIC (Akaike Information Criterion) was developed for measuring the degree of fit of nonlinear regression analysis. A smaller AIC value means a better fit).

We confirmed that the growth trajectories of the three different products followed three different paths: televisions can be identified best as following the simple logistic curve, where the upper limit does not change, as can be seen in Figure 8. In retrospect, this result is good quantitative evidence that the innovation of TVs still remains in the first innovation cycle without any change of upper limit experienced.

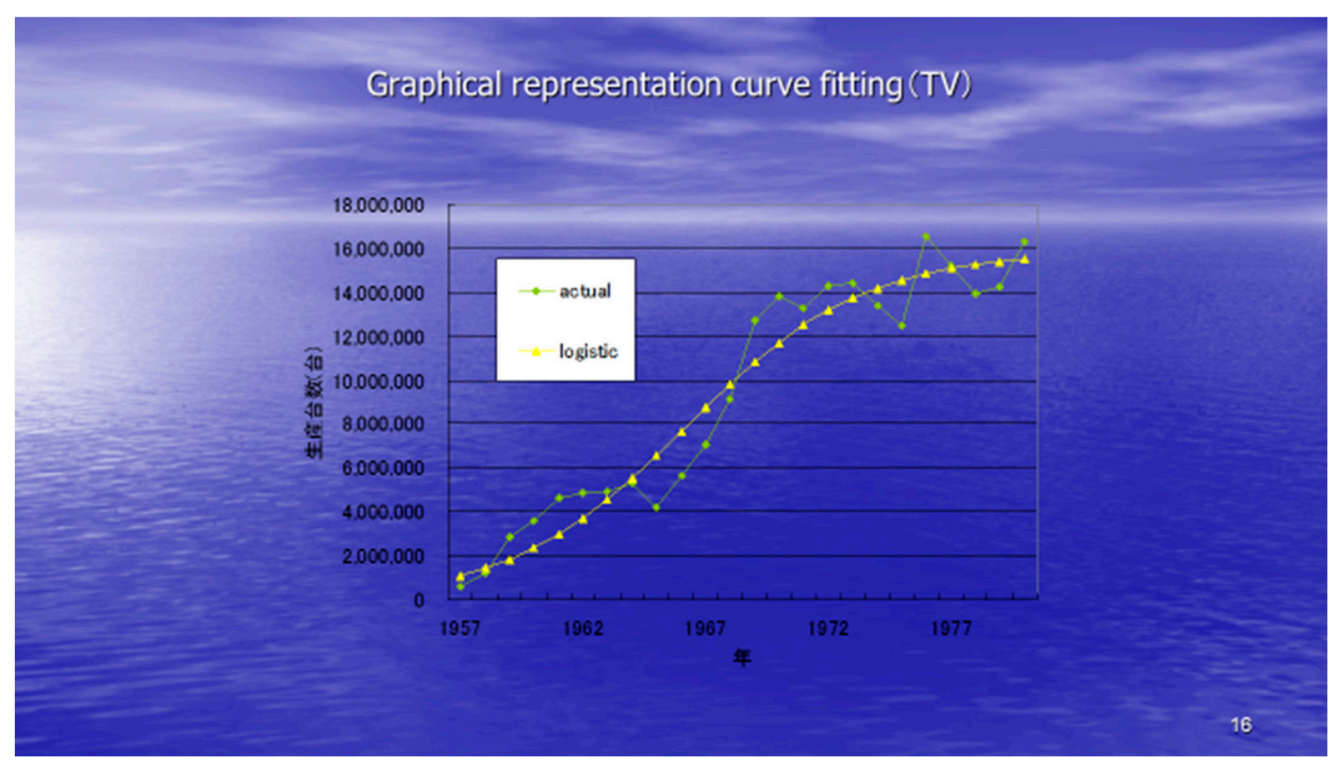

Figure 8. Graphical representation of regression analysis for televisions. Source: Osaki et al. (2001) [26]. 
The growth patterns of printers and PCs are found to follow S-shaped curves where the upper limits also increase. The market growth for printers turns out to be identified best as following the two-step logistic model (model B), as shown in Figure 9. As can be seen in the figure, a stepwise expansion of the potential market size is estimated to have occurred in 1987. Indeed, laser and inkjet printers entered the market in the mid-1980s.

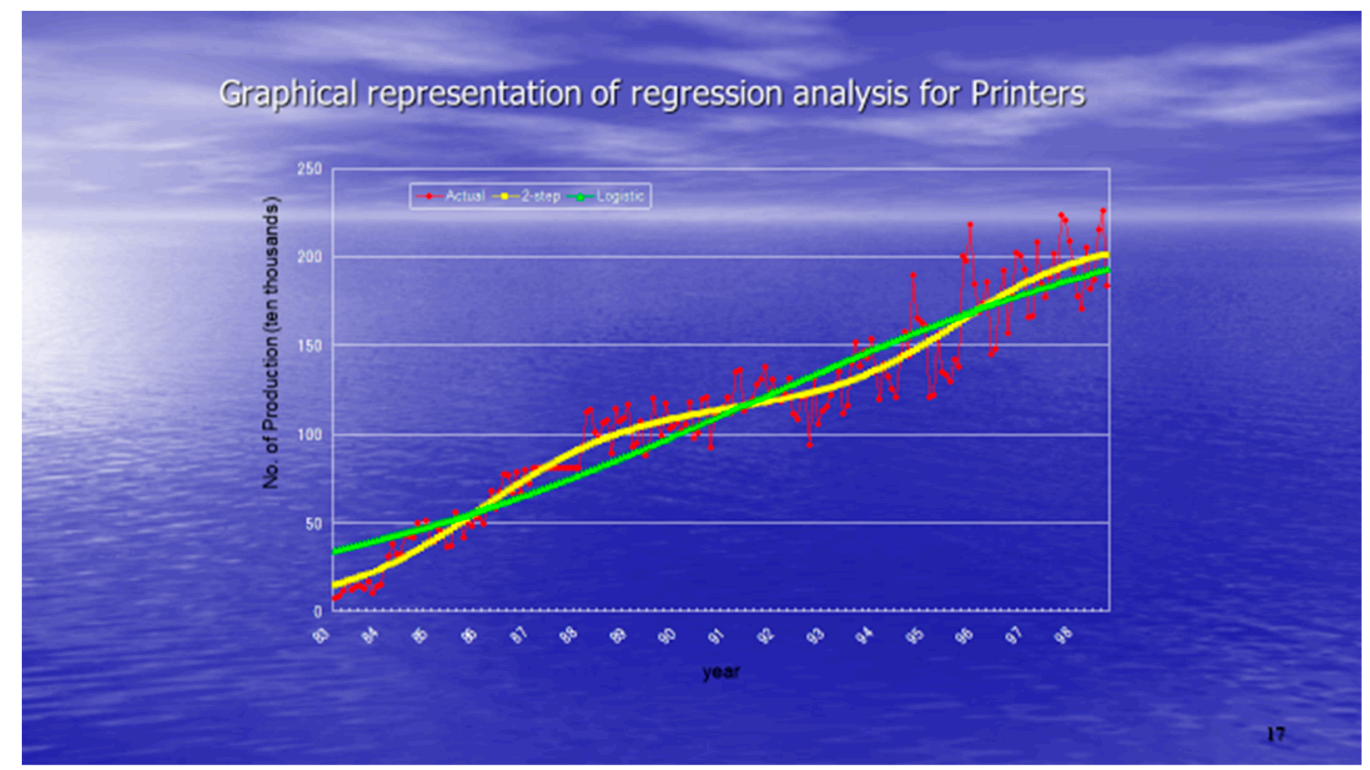

Figure 9. Graphical representation of regression analysis for printers. Source: Osaki et al. (2001) [26].

Apart from the results on printer innovation, the market growth path of PCs, we find, is identified best as following the binomial logistic model (model C), where the upper limit of the potential adopters continuously increases by also following a logistic curve (we might call it a "double-logistic" curve), as seen in Figure 10. This is very different from the patterns of discontinuous innovations. Indeed, a kind of consensus has been reached in several recent empirical studies on what the real implications are of the creation of a "business model" [29-31]. They describe how dynamic business models represent continuous change and therefore make firms constantly learn new and better ways of doing things.

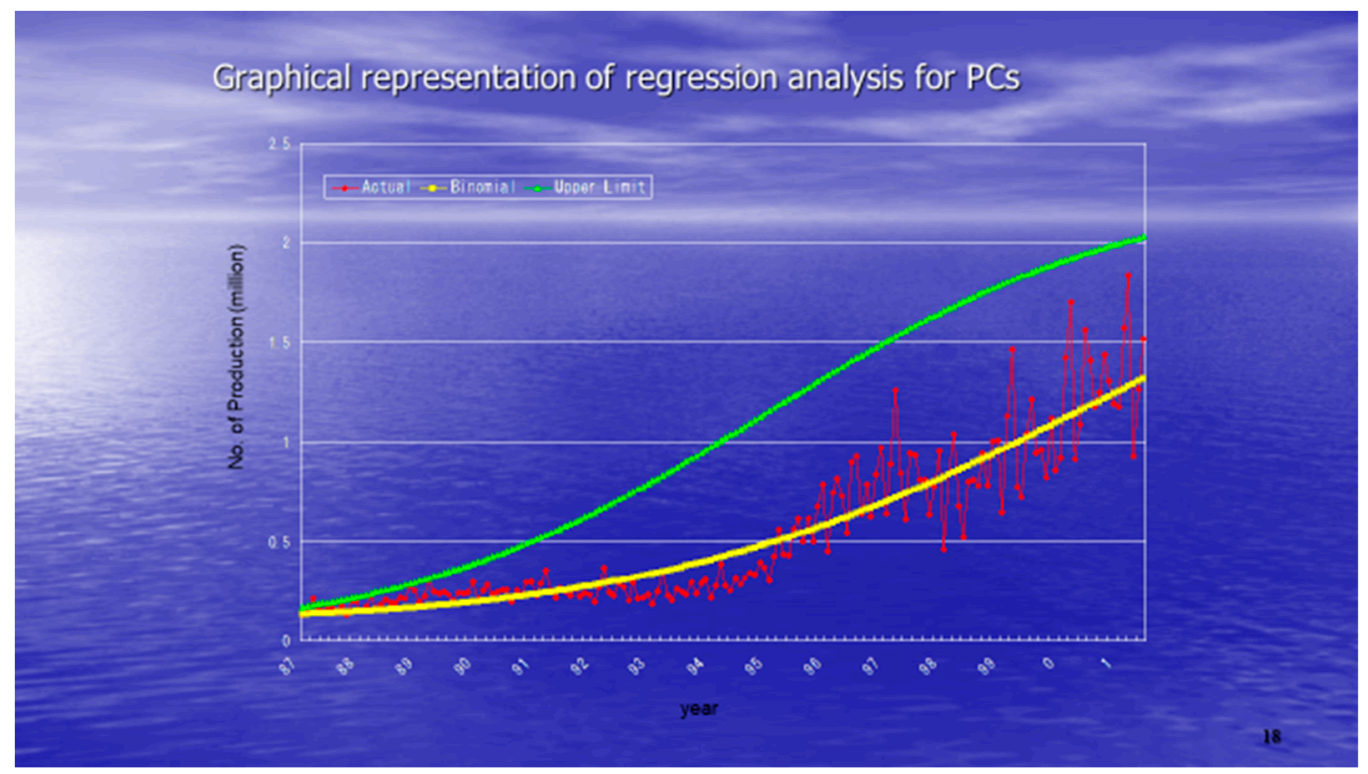

Figure 10. Graphical representation of regression analysis for PCs. Source: Osaki et al. (2001) [26]. 
By modifying Abbate's assertion about the PC industry, we can argue that automobile technology will undergo dramatic changes. The automobile, originally invented as an isolated transportation vehicle, will be reborn as an element of the smart transportation system. Abbate concluded her study: the history of Internet is a history of "surprise" [22]. Indeed, the history of self-driving will be also a history of surprise, or just a history of car's commoditization.

\section{Concluding Remarks}

After reviewing 100 years' development of the automobile industry, we can attempt to reformulate the car industry in a new light. We can ascertain that CPS innovation is occurring in the automobile industry, which we can call the "car renaissance." As we witness the "true automobile" of today, indeed, we realize we had been wandering along through the "dark ages" of the last 100 years since Ford's innovation. In conclusion, we anticipate the CPS revolution will lead us into a highly sophisticated techno-society. Indeed, the techno-renaissance is dawning upon us; it is almost here and not in the distant future as widely predicted.

Funding: This paper was presented as a keynote speech of SOItmC 2019, and the publishing fee was supported by SOItmC.

Conflicts of Interest: The author declares no conflict of interest.

\section{References}

1. Abernathy, W. The Productivity Dilemma: Roadblock to Innovation in the Automobile Industry; Johns Hopkins University Press: Baltimore, MD, USA, 1978.

2. Cole, R.; Yakushiji, T. The American and Japanese Auto Industries in Transition: Report of the Joint U.S.-Japan Automotive Study; University of Michigan (Center for Japanese Studies): Ann Arbor, MI, USA, 1984.

3. Dertouzos, M.; Lester, R.; Solow, R. Made in America: Regaining Productive Edge; MIT Press: Cambridge, MA, USA, 1989.

4. Utterback, J.; Abernathy, W. Dynamic Model of Product and Process Innovation. Omega 1975, 3, 639-656. [CrossRef]

5. Clark, K.; Fujimoto, T. Product Development Performance; Harvard Business School Press: Brighton, MA, USA, 1991.

6. Baldwin, C.; Clark, K. Design Rules: The Power of Modularity; MIT Press: Cambridge, MA, USA, 2000.

7. Yigitcanlar, T.; Wilson, M.; Kamruzzaman, M. Disruptive impacts of automated driving systems on the built environment and land use: An urban planners' perspective. J. Open Innov. Technol. Mark. Complex. 2019, 5, 24. [CrossRef]

8. Utterback, J.; Suarez, F. Innovation, Competition, and Market Structure. Res. Policy 1993, $22,8$.

9. Abernathy, W.; Wayne, K. Limits of the Learning Curve. 1974. Available online: https://hbr.org/1974/09/ limits-of-the-learning-curve (accessed on 31 May 2019).

10. Sloan, A. My Years with General Motors; Doubleday: New York, NY, USA, 1964; pp. 162-163.

11. Kodama, F. New Comers in the World Auto Industry; International Auto Industry Forum: Hakone, Japan, 1984.

12. Fujimoto, T. An Evolutionary Theory of the Production System; Yuhikaku Publishing: Tokyo, Japan, 1997. (In Japanese)

13. Kodama, F. Innovation as a learning process. Bull. Jpn. Soc. Qual. Control 1998, 28, 5-14. (In Japanese)

14. Nishiguchi, T. Strategic Industrial Sourcing; Oxford University Press: Oxford, UK, 1994.

15. Kodama, F.; Yakushiji, T.; Haneda, M. Structural Characteristics of the Japanese Automotive-Supplier Industry (Joint U.S.-Japan Automotive Study); University of Michigan Press: Ann Arbor, MI, USA, 1983.

16. Grove, A. Only the Paranoid Survive; Doubleday Publishing: New York, NY, USA, 1996.

17. Baldwin, C.; Clark, K. Managing in an Age of Modularity. 1997. Available online: https://hbr.org/1997/09/ managing-in-an-age-of-modularity (accessed on 31 May 2019).

18. Ogawa, H. A Study on the Market Growth Model in Which the Potential Demand Increases. Master's Thesis, The University of Tokyo, Tokyo, Japan, 2001.

19. Hayashi, M. An Analysis on Inter-Company Research Collaboration at an Cutomobile Company. Master's Thesis, Shibaura Institute of Technology, Tokyo, Japan, Saitama, Japan, 2008. 
20. German Academy Science and Engineering/Forschungsunion. Securing the Future of German Manufacturing Industry: Recommendations for Implementing the Strategic Initiative INUSTRIE 4.0; German Academy Science and Engineering/Forschungsunion: München, Germany, 2013.

21. Schwab, K. The Fourth Industrial Revolution: What It Means, How to Respond. 2016. Available online: https://www.weforum.org/agenda/2016/01/the-fourth-industrial-revolution-what-it-means-andhow-to-respond/ (accessed on 28 July 2019).

22. Abbate, J. Inventing the Internet; The MIT Press: Cambridge, MA, USA, 1999.

23. Christensen, C.; Rosenbloom, R. Explaining the attacker's advantage: Technological patterns, organizational dynamics and the value network. Res. Policy 1995, 24, 233-257. [CrossRef]

24. Anderson, P.; Tushman, T. Managing through cycles of technological change. Res. Technol. Manag. 1991, 34, 26. [CrossRef]

25. Foster, R. Innovation: The Attacker's Advantage; Summit Books: New York, NY, USA, 1986.

26. Osaki, M.; Gemba, K.; Kodama, F. Market growth models in which the potential market size increases with time. In Proceedings of the PICMET (Portland International Conference on Management of Engineering and Technology), Portland, OR, USA, 29 July-2 August 2001; IEEE: Piscataway, NJ, USA, 2001; pp. 788-796.

27. Kodama, F. Measuring emerging categories of innovation: Modularity and business model. Technol. Forecast. Soc. Chang. 2004, 71, 623-633. [CrossRef]

28. Sharif, M.; Ramanathan, K. Binomial innovation diffusion models with dynamic potential adopter population. Technol. Forecast. Soc. Chang. 1981, 20, 63-87. [CrossRef]

29. Ritala, P.; Sainio, L. Coopetition for radical innovation: Technology, market and business-model perspectives. Technol. Anal. Strateg. Manag. 2014, 26, 2. [CrossRef]

30. Tongur, S.; Engwall, M. The business model dilemma of technology shifts. Technovation 2014, 34, 9. [CrossRef]

31. Mason, K.; Leek, S. Learning to build a supply network: An exploration of dynamic business models. J. Manag. Stud. 2008, 4, 774-799. [CrossRef]

(C) 2019 by the author. Licensee MDPI, Basel, Switzerland. This article is an open access article distributed under the terms and conditions of the Creative Commons Attribution (CC BY) license (http://creativecommons.org/licenses/by/4.0/). 